\title{
JORNADA DE INVESTIGACIÓN EN DERECHO Y CIENCIAS FORENSES
}

Donde se dará a conocer el desarrollo investigador en el área de la criminalística, las ciencias forenses y el derecho

DELDERECHOYLA CRIMINALLISTICA

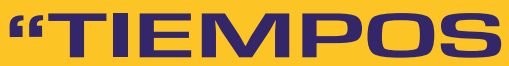

CONVULSOS"

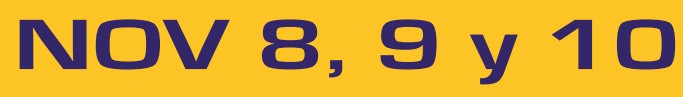

\section{Conferencista invitada}

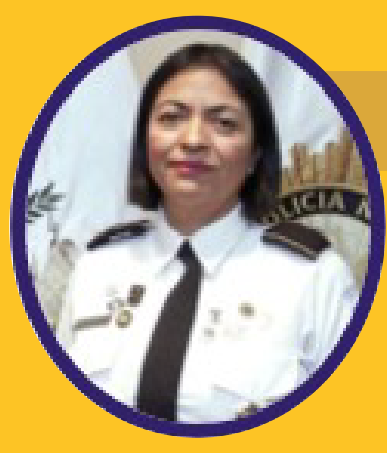

Roxana Alvarado Márquez

NOV 12

\section{Perito Lofoscopista}

Agente de la Policía Nacional Civil (PNC) de Guatemala Hora: 8:00 a.m

Potencia: La identificación a través de los Sistemas Biométricos, AFIS - ABIS y dispositivos móviles de identificación IN SITU

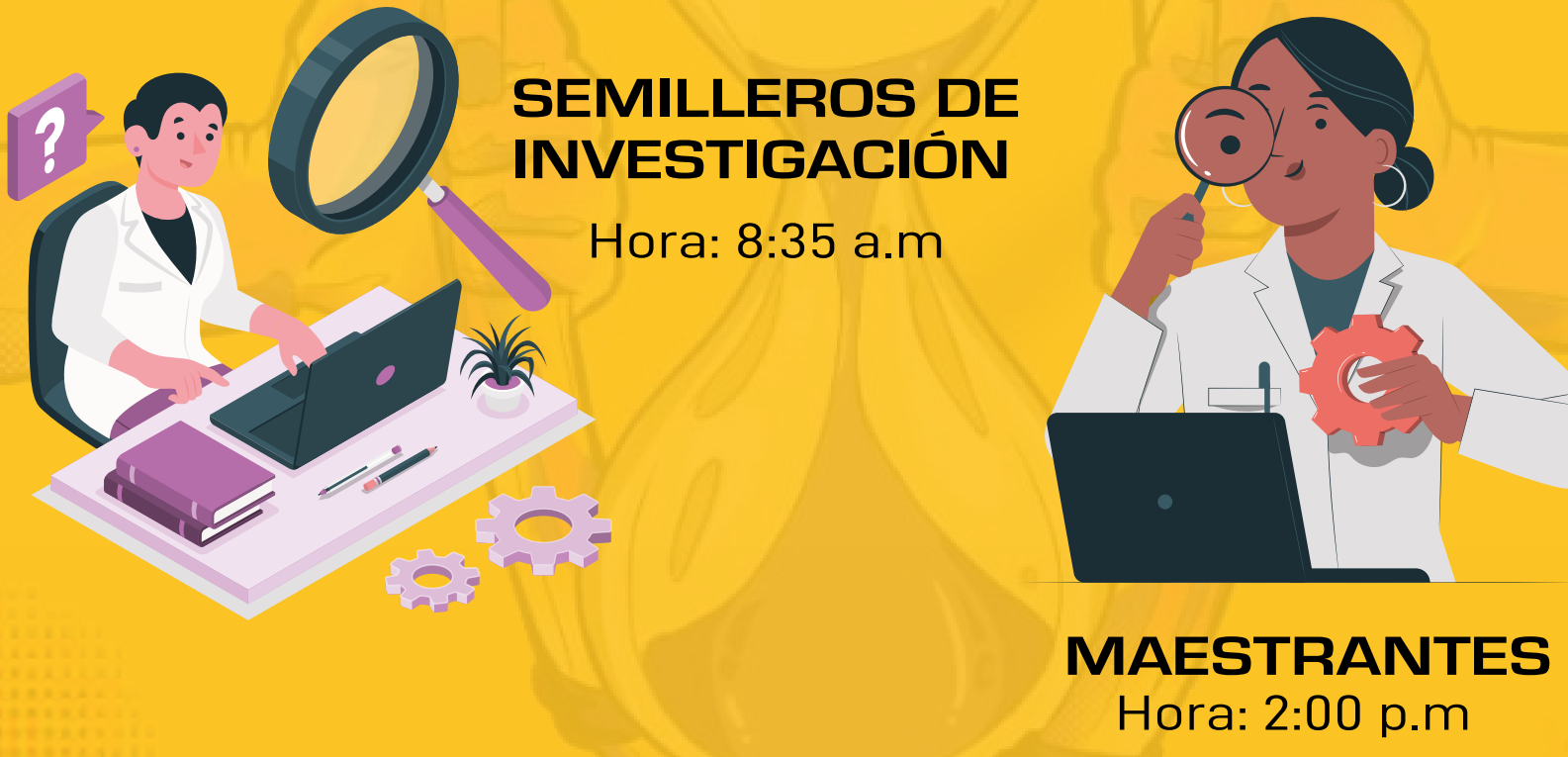

https://renata.zoom.us/j/7812506833

Tecnológica de Antioquia

Institución Universitaria

VIGILADA MINEDUCACIÓN
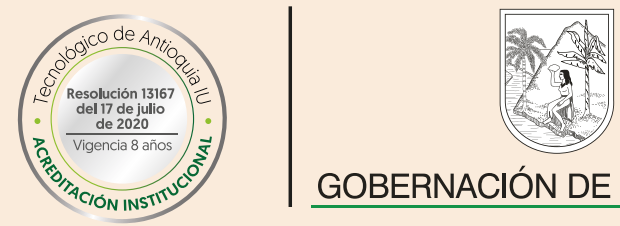

GOBERNACIÓN DE ANTIOQUIA

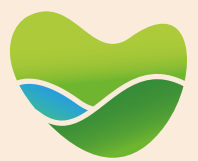

UNIDOS 


\section{JORNADA DE INVESTIGACIÓN EN DERECHO Y CIENCIAS FORENSES}

\begin{tabular}{|c|c|c|c|}
\hline \multicolumn{4}{|c|}{ Programación } \\
\hline Fecha & Hora & Semillero de investigación & Nombre del trabajo \\
\hline $12 / 11 / 21$ & 8:00 & $\begin{array}{c}\text { Ponencia Magistral "La identificación } \\
\text { a través de los sistemas biométricos, } \\
\text { AFIS-ABIS y dispositivos móviles de } \\
\text { identificación in situ" }\end{array}$ & \\
\hline $12 / 11 / 21$ & 8:35 & Multidisciplinar de Ciencias Forenses & \\
\hline $12 / 11 / 21$ & 8:45 & Toxicología Forense & $\begin{array}{c}\text { Conocimiento y uso de cannabinoides } \\
\text { sintéticos en estudiantes del Tecnológico } \\
\text { de Antiqouia, Medellín } 2020\end{array}$ \\
\hline $12 / 11 / 21$ & 9:00 & Multidisciplinar de Ciencias Forenses & $\begin{array}{c}\text { Herramienta tipo encuesta para la } \\
\text { resolución de un caso Forense en } \\
\text { Desaparición Forzada }\end{array}$ \\
\hline $12 / 11 / 21$ & 9:15 & Bioinformática & $\begin{array}{c}\text { Redes filogenéticas para la identificación } \\
\text { molecular de especies del género Lucilia } \\
\text { (Diptera: Calliphoridae), moscas de } \\
\text { importancia forense" }\end{array}$ \\
\hline $12 / 11 / 21$ & 9:30 & Bioinformática & $\begin{array}{l}\text { Redes neuronales: de las hormigas a la } \\
\text { mitigación de los embotellamientos en la } \\
\text { cuidad }\end{array}$ \\
\hline $12 / 11 / 21$ & 9:45 & INSECTA & $\begin{array}{l}\text { Reservorio la diversidad: colección de ADN } \\
\text { de moscas de importancia forense del } \\
\text { Tecnológico de Antioquia }\end{array}$ \\
\hline $12 / 11 / 21$ & 10:00 & $\begin{array}{c}\text { Seguridad Social - El derecho a la salud } \\
\text { como derecho fundamental - Sentencia T } \\
760 / 2008\end{array}$ & $\begin{array}{l}\text { La salud como derecho fundamental } \\
\text { autónomo - a través del análisis } \\
\text { jurisprudencial de la sentencia t-760 } \\
\text { de } 2008\end{array}$ \\
\hline $12 / 11 / 21$ & 10:15 & $\begin{array}{l}\text { Ágora, en estructura y funcionamiento del } \\
\text { Estado }\end{array}$ & $\begin{array}{c}\text { El control ciudadano en Colombia a través } \\
\text { de los mecanismos de participación }\end{array}$ \\
\hline $12 / 11 / 21$ & 10:30 & Victimología y Criminología & \\
\hline $12 / 11 / 21$ & $10: 45$ & Victimología y Criminología & $\begin{array}{c}\text { Influencia de las redes sociales en la } \\
\text { ideación suicida en adolescentes del } \\
\text { corregimiento Sabaletas del municipio } \\
\text { de Montebello, Antioquia }\end{array}$ \\
\hline $12 / 11 / 21$ & $11: 00$ & Victimología y Criminología & $\begin{array}{c}\text { Duelo ante la ausencia de cuerpo por } \\
\text { conflicto armado en el municipio de } \\
\text { Granada, Antioquia }\end{array}$ \\
\hline
\end{tabular}




\begin{tabular}{|c|c|c|c|}
\multicolumn{5}{|c}{ Fecha } & Hora & Semillero de investigación & \multicolumn{1}{c|}{ Nombre del trabajo } \\
\hline $12 / 11 / 21$ & $11: 15$ & $\begin{array}{c}\text { Derechos Humanos, Género y } \\
\text { Multiculturalismo }\end{array}$ & $\begin{array}{c}\text { El enigma de los asesinatos de líderes } \\
\text { sociales en el Paćfico colombiano y su } \\
\text { relación con las industrias extractivas }\end{array}$ \\
\hline $12 / 11 / 21$ & $11: 30$ & $\begin{array}{c}\text { Ciencias exactas y ciencias prácticas } \\
\text { en la formación del Juriconsulto }\end{array}$ & $\begin{array}{c}\text { Diálogos de saberes entre las diferentes } \\
\text { ciencias desde la legalidad y la conducta } \\
\text { humana }\end{array}$ \\
\hline $12 / 11 / 21$ & $11: 45$ & $\begin{array}{c}\text { Derechos Humanos, Género y } \\
\text { Multiculturalismo }\end{array}$ & $\begin{array}{c}\text { Procesos de justicia transicional sin } \\
\text { transiciones: estudio relativo a Colombia } \\
\text { y España }\end{array}$ \\
\hline $12 / 11 / 21$ & $12: 00$ & Filosofía y Decisión Judicial & $\begin{array}{c}\text { La hermenéutica constitucional como } \\
\text { instrumento legitimador de la decisión } \\
\text { judicial en los fallos de tutela en Colombia }\end{array}$ \\
\hline $12 / 11 / 21$ & $12: 30$ & Premiación y Cierre & \\
\hline
\end{tabular}

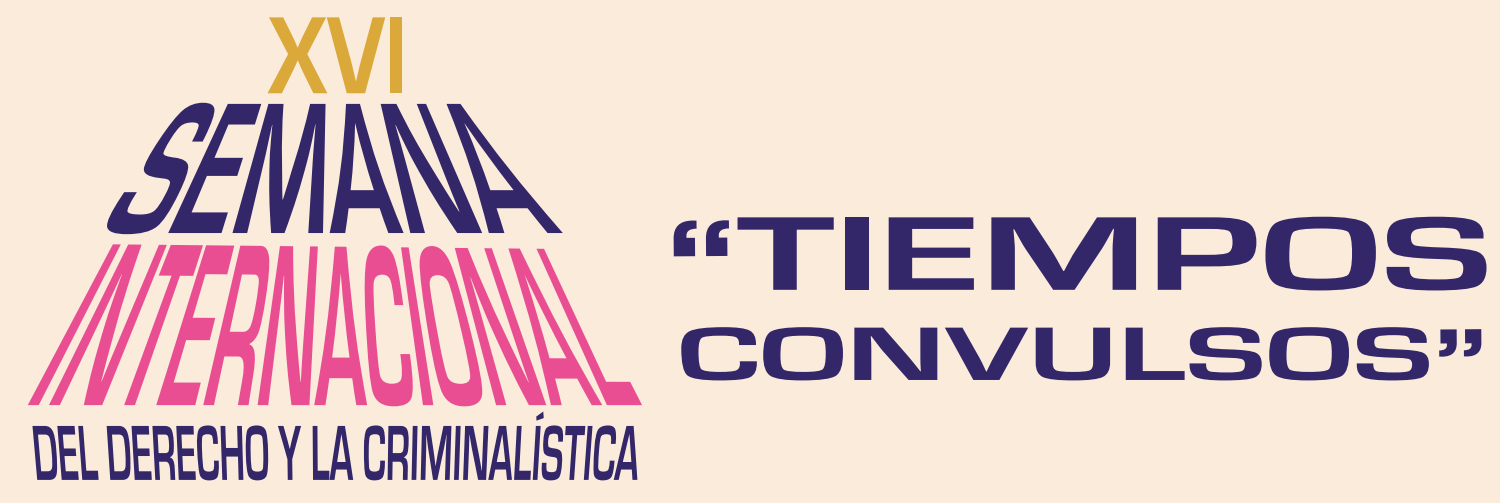

Tecnológico de Antioquia Institución Universitaria VIGILADA MINEDUCACIÓN

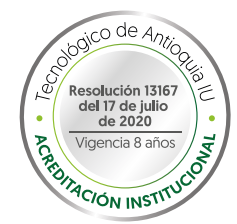




\section{Implementación de Estrategias de Justicia Restaurativa en Personas con Trastornos Mentales que han Cometido Hechos Delictivos en Colombia}

\section{Laura Arenas Tabares}

Tecnológico de Antioquia - Institución Universitaria Facultad de Derecho y Ciencias Forenses

Semillero multidisciplinar de ciencias forenses

Grupo de investigación BISMA

Medellín, Colombia

laura.arenas@correo.tdea.edu.co

\section{Michelle Barco Flórez}

Tecnológico de Antioquia - Institución Universitaria Facultad de Derecho y Ciencias Forenses

Semillero multidisciplinar de ciencias forenses

Grupo de investigación BISMA

Medellín, Colombia

michelle.barco@correo.tdea.edu.co

\author{
Mariana Ospina Arango \\ Tecnológico de Antioquia - Institución Universitaria \\ Facultad de Derecho y Ciencias Forenses \\ Semillero multidisciplinar de ciencias forenses \\ Grupo de investigación BISMA \\ Medellín, Colombia \\ mariana.ospina35@correo.tdea.edu.co
}

\section{Aura María Gil Villa}

Tecnológico de Antioquia - Institución Universitaria Facultad de Derecho y Ciencias Forenses

Coordinadora del semillero multidisciplinar de ciencias forenses

Grupo de investigación BISMA

Docente investigadora. Bióloga. Magíster en biotecnología y fisiología. Doctora en bioquímica, farmacología y fisiología

Medellín, Colombia

aura.gil@tdea.edu.co

DOI: https://doi.org/10.53995/25390147.1013

Los trastornos mentales afectan el estado de ánimo, así como el pensamiento y comportamiento. Se clasifican según su esfera mental perjudicada y algunos pueden interferir en el aspecto volitivo y la toma de decisiones. La justicia ordinaria persigue y juzga los delitos cometidos en un territorio, pero esta presenta problemas en su aplicación, porque se centra únicamente en el castigo y olvida a la víctima; además, personas con trastornos mentales que han cometido delitos, se someten a una justicia sin garantía, lo que impide lograr una resocialización efectiva ni un tratamiento, y sufren una doble estigmatización, asociado al trastorno mental y al medio penitenciario. Por su parte, en un estudio realizado en Holanda, se demostró que, aunque los victimarios sufran de un trastorno mental y cometan un delito grave, pueden tener contacto con la víctima y generar beneficios para ambas partes. Así, debido a estos problemas de la justicia ordinaria, se propone como objetivo principal, identificar en el actual sistema penal colombiano estrategias penales enmarcadas en la justicia restaurativa, aplicadas a personas con alteraciones mentales que han cometido hechos delictivos, para así lograr la solución de conflictos mediante el diálogo y acercamiento de la víctima, victimario y la comunidad. 


\title{
Situación de los Grupos Vulnerables en las Cárceles de Colombia entre los Años 2009-2021
}

\author{
Juan Alejandro Calderón Hernández \\ Tecnológico de Antioquia - Institución Universitaria \\ Facultad de Derecho y Ciencias Forenses \\ Semillero multidisciplinar de ciencias forenses \\ Grupo de investigación BISMA \\ Profesional en criminalística \\ Medellín, Antioquía \\ Juan.calderon69@correo.tdea.edu.co

\section{Carolina Quintero Valencia} \\ Tecnológico de Antioquia - Institución Universitaria \\ Facultad de Derecho y Ciencias Forenses \\ Semillero multidisciplinar de ciencias forenses \\ Grupo de investigación BISMA \\ Profesional en criminalística \\ Medellín, Antioquía \\ Carolina.quintero68@correo.tdea.edu.co
}

\author{
Aura María Gil Villa \\ Tecnológico de Antioquia - Institución Universitaria \\ Facultad de Derecho y Ciencias Forenses \\ Coordinadora del semillero multidisciplinar de \\ ciencias forenses \\ Grupo de investigación BISMA \\ Docente investigadora. Bióloga. Magíster en \\ biotecnología y fisiología. Doctora en bioquímica, \\ farmacología y fisiología \\ Medellín, Colombia \\ aura.gil@tdea.edu.co
}

DOI: https://doi.org/10.53995/25390147.1013

Un grupo vulnerable se define como un conjunto de personas relacionadas entre sí por un aspecto particular que los hace susceptibles al rechazo por parte de la sociedad. Colombia es un país que posee diferentes problemáticas estructurales y sociales, viéndose reflejado en la situación que se vive al interior de las cárceles desde hace varias décadas; las cárceles son el principal lugar para cumplir la pena de privación de la libertad y están enmarcadas por el hacinamiento, el cual conlleva insalubridad y falta de reglamentación. Existen grupos poblacionales dentro de los establecimientos carcelarios que son susceptibles, bien sea, por su condición socioeconómica, religiosa, sexual o su estado de salud física y mental; estos grupos son los que representan estadísticamente la mayor población de víctimas de violencia física, sexual y psicológica al interior de los centros de reclusión. En este escenario, es importante entender que en un contexto en el cual todas las personas viven despojadas de necesidades fundamentales, los individuos que hacen parte de los grupos vulnerables se ven directamente más afectados que la población general, ya que sus necesidades no son tratadas de una forma idónea y digna. Por lo anterior, se realizó un análisis y clasificación de los grupos vulnerables identificados en las cárceles de Colombia entre el período 2009-2021, con el fin de contrastar las arbitrariedades dentro de la política criminal del país y proponer cambios en la misma. 


\title{
Redes Filogenéticas para la Identificación Molecular de Especies del Género Lucilia (Diptera: Calliphoridae), Moscas de Importancia Forense
}

\author{
Viviana Castillo Vanegas \\ Luz Miryam Gómez Piñerez \\ Eduardo Amat, Andrés López Rubio \\ Tecnológico de Antioquia - Institución Universitaria \\ Facultad de Derecho y Ciencias Forenses \\ Semillero de bioinformática \\ Grupo Bioforense
}

DOI: https://doi.org/10.53995/25390147.1013

Dentro del gremio de insectos de importancia forense, el género Lucilia (Diptera: Calliphoridae) cobra relevancia por su diversidad y por encontrarse dentro de los primeros colonizadores en los procesos de sucesión cadavérica. Para su aplicabilidad en determinar el intervalo posmorten, en casos de negligencia, abuso y maltrato de humanos y animales, se hace necesario contar con una identificación taxonómica precisa. El uso de secuencias del gen mitocondrial COI se ha propuesto como complemento a esta identificación, principalmente en casos donde la taxonomía con base en caracteres morfológicos se dificulta, y para lo cual existen diversas aproximaciones. El objetivo de este trabajo es analizar la utilidad de las redes de filogenéticas para la identificación de las especies del género Lucilia como contribución a su taxonomía. Se incluyeron especímenes de Brasil, Perú, Venezuela, Ecuador, Suecia y Colombia. Se estimó un árbol y una red filogenética a partir de secuencias de ADN del gen mitocondrial COI. En el dendrograma y la red filogenética se encontraron tres grupos: (I) L. caesar y L. ilustris, (II) L. sericata y (III) L. cuprina, conformados por el resto de especies empleadas en el estudio. La topología de la red presentó una mayor resolución en la diferenciación entre especies. Estos resultados validan el uso de estrategias de redes filogenéticas para el estudio de límites de especies. Se recomienda la incorporación de datos de origen nuclear para esclarecer los eventos de hibridación y complementar la determinación de especie de estos insectos de importancia forense. 


\title{
La Importancia del Criminalista en Empresas de Vigilancia y Seguridad Privada en Colombia
}

\author{
Mateo Esteban Ceballos Agudelo \\ Tecnológico de Antioquia - Institución Universitaria \\ Facultad de Derecho y Ciencias Forenses \\ Semillero multidisciplinar de ciencias forenses \\ Grupo de investigación BISMA \\ Medellín, Colombia \\ mtfrns@gmail.com
}

\author{
Adriana Melissa López Fabre \\ Tecnológico de Antioquia - Institución Universitaria \\ Facultad de Derecho y Ciencias Forenses \\ Semillero multidisciplinar de ciencias forenses \\ Grupo de investigación BISMA \\ Medellín, Colombia \\ melissafabre18@gmail.com
}

\author{
Yulieth Catalina Lozano Escudero \\ Tecnológico de Antioquia - Institución Universitaria \\ Facultad de Derecho y Ciencias Forenses \\ Semillero multidisciplinar de ciencias forenses \\ Grupo de investigación BISMA \\ Medellín, Colombia. \\ lozanokatalina99@gmail.com \\ Aura María Gil Villa \\ Tecnológico de Antioquia - Institución Universitaria. \\ Facultad de Derecho y Ciencias Forenses \\ Coordinadora del semillero multidisciplinar de \\ ciencias forenses \\ Grupo de investigación BISMA \\ Docente investigadora. Bióloga. Magíster en \\ Biotecnología y Fisiología. Doctora en bioquímica, \\ farmacología y fisiología \\ Medellín, Colombia \\ aura.gil@tdea.edu.co
}

DOI: https://doi.org/10.53995/25390147.1013

\begin{abstract}
Diversos contextos enmarcan ambientes susceptibles para la comisión de un delito, por lo que llevar a la criminalística a la esfera corporativa implica extender su alcance hasta el campo de la seguridad y la vigilancia. En Colombia, las limitaciones dispuestas por la SuperVigilancia, reflejadas en el estatuto de vigilancia y seguridad privada, dejan abiertos vacíos en la normatividad que dificultan el alcance del concepto de investigador privado y las posibilidades de su actuar; a diferencia de modelos europeos que no solo cualifican a los investigadores privados, sino que señalan su campo de acción en los procesos, tanto penales como civiles. Por lo anterior, la presente propuesta de investigación pretende identificar las competencias y las habilidades del criminalista con respecto a las necesidades requeridas en esta área por las empresas de vigilancia y seguridad privada acreditadas por la SuperVigilancia, quienes son las que responden a la demanda de los diferentes sectores empresariales en Colombia. Para lograr el objetivo, se han revisado los programas académicos de profesional en criminalística (Tecnológico de Antioquia) e investigación criminal (Universidad de Medellín) con base en las categorías de servicios de las empresas acreditadas, para luego confrontarlas con el estándar internacional (ASIS). Como producto final del proyecto se espera dejar a disposición un portafolio de servicios que integre la información obtenida.
\end{abstract}




\section{Lenguaje no Verbal en las Entrevistas Criminales}

\section{Nely Ximena Espinosa}

Tecnológico de Antioquia - Institución Universitaria Facultad de Derecho y Ciencias Forenses

Semillero multidisciplinar de ciencias forenses

Grupo de investigación BISMA

Profesional en criminalística

Medellín, Colombia

nellyximena.07@gmail.com

\section{Edwin Barrios}

Tecnológico de Antioquia - Institución Universitaria

Facultad de Derecho y Ciencias Forenses

Semillero multidisciplinar de ciencias forenses

Grupo de investigación BISMA

Profesional en criminalística

Medellín, Colombia

barriose272@gmail.com

\section{Alejandro Gómez}

Tecnológico de Antioquia - Institución Universitaria

Facultad de Derecho y Ciencias Forenses

Semillero multidisciplinar de ciencias forenses

Grupo de investigación BISMA

Profesional en criminalística

Medellín, Colombia

ozzamaa08@gmail.com

\section{Aura María Gil Villa}

Tecnológico de Antioquia

Facultad de Derecho y Ciencias Forenses

Coordinadora del semillero multidisciplinar de ciencias forenses

Grupo de investigación BISMA

Docente investigadora. Bióloga. Magíster en biotecnología y fisiología. Doctora en bioquímica, farmacología y fisiología

Medellín, Colombia

aura.gil@tdea.edu.co

El lenguaje no verbal aplicado en las entrevistas criminales, también conocidas como entrevistas forenses dentro del marco jurídico colombiano, se define como indicadores gestuales de una persona que muestra la veracidad de sus palabras; es decir, el lenguaje no verbal es aquel que se manifiesta en una persona a través de todo su cuerpo, y que a su vez logra contestar a interrogantes que crean los investigadores mientras se desarrolla la entrevista, mediante preguntas que permiten distinguir si la persona miente o dice la verdad.

El enfoque más destacado en una entrevista forense es el de las expresiones faciales de la persona, la gestualidad de su cuerpo, postura corporal e incluso la apariencia física de la misma. Por lo anterior, el objetivo de la presente propuesta es determinar si los tipos de lenguajes no verbales que se utilizan en una entrevista convencional tienen validez en el sistema penal colombiano cuando son utilizadas en el área de la criminalística y sus afines. 


\section{Efecto de las Anormalidades Congénitas e Inducidas sobre la Configuración de las Huellas Dactilares}

\section{María Alejandra Galeano Tava}

Tecnológico de Antioquia - Institución Universitaria Facultad de Derecho y Ciencias Forenses Semillero multidisciplinar de ciencias forenses Grupo de investigación BISMA

Profesional en criminalística Medellín, Colombia maria.galeano88@correo.tdea.edu.co

\section{Mariana Saraz Correa}

Tecnológico de Antioquia Institución Universitaria Facultad de Derecho y Ciencias Forenses Semillero multidisciplinar de ciencias forenses Grupo de investigación BISMA

Profesional en criminalística Medellín, Colombia mariana.saraz87@correo.tdea.edu.co

\section{Santiago Hernández Mesa}

Tecnológico de Antioquia - Institución Universitaria Facultad de Derecho y Ciencias Forenses Semillero multidisciplinar de ciencias forenses Grupo de investigación BISMA

Profesional en criminalística Medellín, Colombia santiago.hernandez18@correo.tdea.edu.co

\section{Aura María Gil Villa}

Tecnológico de Antioquia - Institución Universitaria Facultad de Derecho y Ciencias Forenses

Coordinadora del semillero multidisciplinar de ciencias forenses

Grupo de investigación BISMA

Docente investigadora. Bióloga. Magíster en biotecnología y fisiología. Doctora en bioquímica, farmacología y fisiología

Medellín, Colombia

aura.gil@tdea.edu.co

DOl: https://doi.org/10.53995/25390147.1013

La identificación lofoscópica es uno de los métodos más relevantes y eficientes en el ámbito forense, en donde deberían considerarse las anormalidades que podrían afectar este método al momento de su aplicación, como son aquellas derivadas de eventos congénitos y las inducidas después del nacimiento y durante la vida del individuo. Teniendo en cuenta, la importancia de reconocer anormalidades dactilares existentes en la población colombiana como información complementaria a la proporcionada por otros métodos de identificación en el área dactiloscópica; el objetivo de la presente propuesta de investigación, es describir anormalidades congénitas e inducidas que puedan influir sobre la configuración de las huellas dactilares de un individuo para eventos de identificación en un contexto forense en Antioquia. Para lograr este objetivo, se creó una herramienta de solicitud de información dirigida a diferentes entidades como Instituto Nacional de Medicina Forense, Fiscalía General de la Nación, Registraduría Nacional y algunas entidades hospitalarias, las cuales tienen acceso a casos relacionados con anormalidades dactilares congénitas e inducidas. Se pretende que, a partir de los resultados obtenidos, se logre establecer un estimado del número de personas en Antioquia que poseen estas anormalidades, y así obtener un registro que permita la construcción de una base de datos complementaria a las herramientas empleadas en la dactiloscopia para procesos de identificación de personas. 


\title{
Diálogos de Saberes entre las Diferentes Ciencias, desde la Legalidad y la Conducta Humana
}

\author{
Melissa Garcia Betancur \\ Tecnológico de Antioquia - Institución Universitaria \\ Facultad de Derecho y Ciencias Forenses y Facultad \\ de Educación y Ciencias Sociales \\ Semillero de investigación \\ Ciencias exactas y ciencias prácticas en la forma- \\ ción del jurisconsulto \\ Medellín, Colombia \\ Estudiante de derecho \\ melissa.garcia@correo.tdea.edu.co \\ Valeria García Betancur \\ Tecnológico de Antioquia - Institución Universitaria \\ Facultad de Derecho y Ciencias Forenses y Facultad \\ de Educación y Ciencias Sociales \\ Semillero de investigación \\ Ciencias exactas y ciencias prácticas en la forma- \\ ción del jurisconsulto \\ Medellín, Colombia \\ Estudiante de psicología \\ valeria.garcia82@correo.tdea.edu.co
}

DOI: https://doi.org/10.53995/25390147.1013

Desde los años anteriores, se evidencia cómo la ciencia ha evolucionado y las diferentes concepciones que han traído para describir la conducta humana. Es por esto que es importante recalcar cómo el derecho y la psicología se entrelazan, para explicar cada uno de los sucesos que han tenido que ver con las conductas y procedencias de los seres humanos.

Cuando surgió el periodo científico, en materia de derecho, se establecieron varias concepciones que contribuyeron al sistema actual, es decir, estos elementos científicos que surgieron en ese entonces ayudaron a que la humanidad evolucionara. De esta manera, es importante explicar cada una de las ciencias, para comprender cómo la legalidad surgió y cómo la piscología ha sido una herramienta de análisis y comprensión para entender la conducta humana en el derecho. 


\section{Variantes en Genes Asociados a Rasgos Fenotípicos del Rostro en la Población Mexicana}

\author{
Anette Roxana Gastelum Quiroz \\ Universidad Autónoma de Occidente \\ Unidad Regional Mazatlán \\ Mazatán, Sinaloa, México \\ 18050515@uadeo.mx
}

\author{
Aura María Gil Villa \\ Tecnológico de Antioquia - Institución Universitaria \\ Facultad de Derecho y Ciencias Forenses \\ Coordinadora del semillero multidisciplinar de \\ ciencias forenses \\ Grupo de investigación BISMA \\ Docente investigadora. Bióloga. Magíster en \\ biotecnología y fisiología. Doctora en bioquímica, \\ farmacología y fisiología \\ Medellín, Colombia \\ aura.gil@tdea.edu.co
}

\author{
María Victoria Parra Marín \\ Tecnológico de Antioquia - Institución Universitaria \\ Facultad de Derecho y Ciencias Forenses \\ Grupo de investigación CBATA \\ Bióloga. Magíster en ciencias básicas biomédicas. \\ Doctora en biología \\ Medellín, Colombia \\ parra.v@gmail.com
}

DOI: https://doi.org/10.53995/25390147.1013

El retrato hablado es una técnica de identificación empleada en las investigaciones policiales; es una actividad que se realiza manualmente, lo cual hace que esta manera de reconocimiento sea lenta, llegando a casos donde no se obtiene ningún resultado. Se emplean también técnicas más novedosas como el reconocimiento facial y el perfil genético que es el más usado; sin embargo, no siempre se obtienen resultados satisfactorios. En estos casos, se puede emplear la técnica de fenotipado de ADN, la cual predice características externamente visibles a partir de ADN. El sistema de fenotipado que en la actualidad está disponible, solamente predice el color de ojos, cabello y piel, por lo que el objetivo de esta investigación fue identificar variantes en genes asociados a rasgos fenotípicos del rostro, útiles para el reconocimiento facial en el área de ciencias forenses y criminalística.

La investigación se basó en la búsqueda de artículos científicos recientes; adicionalmente, se hará una búsqueda de variantes en la base de datos del proyecto 1000 genomas, en donde se consultarán las frecuencias de las variantes para evaluar si es factible o no incluirlas en una batería de marcadores para fenotipado.

En la población latinoamericana, se han encontrado polimorfismos como el $2 \mathrm{q} 12$ asociados a la forma del cuero cabelludo y grosor de la barba y las cejas; así también en las regiones $1 p 13.3$ y $21 q 21.2$ se asociaron con arrugas; $1 q 32.3$ con el recuento de lunares; y $5 p 13.2$ y 1 p13.3 con ambas. 


\title{
El Control Ciudadano en Colombia, a través de los Mecanismos de Participación
}

\author{
Juan Pablo Giraldo Ramírez \\ Alexandra Restrepo Gallego \\ Eliana María Guzmán Álvarez \\ Santiago Alberto Pérez Sáenz \\ Elkin De Jesús Vergara Marín \\ Yesenia Caicedo Castrillón \\ alexandra.restrepo52@correo.tdea.edu.co \\ Tecnológico de Antioquia - Institución Universitaria \\ Facultad de Derecho y Ciencias Forenses \\ Semillero AGORA en estructura y funcionamiento \\ del Estado \\ Grupo de investigación jurídico social \\ Medellín, Colombia
}

DOI: https://doi.org/10.53995/25390147.1013

Colombia adoptó como forma de gobierno el régimen representativo, el cual permite a los electores controlar las malas decisiones que tomen sus representantes elegidos. Este control quiso ser reforzado en la constitución de 1991 con la adopción de varios mecanismos de participación ciudadana. Sin embargo, cuando se analiza la efectividad de los controles ciudadanos por medio de los mecanismos de participación como forma de control a los representantes que actúen de manera incorrecta en su ejercicio de representación, se evidencia que la normativa del país dificulta en lo práctico que los electores puedan hacer responsables a sus representantes por una mala función. La Ley 1757 de 2015 enuncia los mecanismos de participación ciudadana: la iniciativa popular legislativa y constitucional, el cabildo abierto, la revocatoria de mandato y el referendo son de origen popular; mientras que el plebiscito, la consulta popular y el referendo tienen origen en las autoridades públicas. Además de estos, la Ley 1755 de 2015 declara que el derecho fundamental de petición es también un mecanismo de participación democrática. Dichos mecanismos deben ser el medio para ejercer control político y ciudadano a los funcionarios públicos y a sus actos. Se identificó cual es la finalidad descrita en la ley de cada uno de estos mecanismos y el procedimiento que se debe seguir para su puesta en práctica, y se observó que muchos de estos mecanismos no están en capacidad de lograr el fin perseguido, porque el control ejercido por la ciudadanía queda sujeto a la voluntad política para hacerlos efectivos y generar sanciones en caso necesario. 


\section{Importancia de la Implementación de Normativas Dirigidas al Hacking Ético en Colombia}

Sarah Gómez Cortínez

Tecnológico de Antioquia - Institución Universitaria

Facultad de Derecho y Ciencias Forenses

Semillero multidisciplinar de ciencias forenses

Grupo de investigación BISMA

Profesional en criminalística

Medellín, Colombia

sarah138304@gmail.com

\section{Luisa María Moreno Alzate}

Tecnológico de Antioquia - Institución Universitaria

Facultad de Derecho y Ciencias Forenses

Semillero multidisciplinar de ciencias forenses

Grupo de investigación BISMA

Profesional en criminalística

Medellín, Colombia

Lui-moreno@hotmail.com

\section{Brayan Alexander Quiroz Flórez}

Tecnológico de Antioquia - Institución Universitaria

Facultad de Derecho y Ciencias Forenses

Semillero multidisciplinar de ciencias forenses

Grupo de investigación BISMA

Profesional en criminalística

Medellín, Colombia

bquiroz@correo.tdea.edu.co
Mariana Ramírez Gómez

Tecnológico de Antioquia - Institución Universitaria

Facultad de Derecho y Ciencias Forenses

Semillero multidisciplinar de ciencias forenses

Grupo de investigación BISMA

Profesional en criminalística

Medellín, Colombia

mariana.ramirez@correo.tdea.edu.co

\author{
Aura María Gil Villa \\ Tecnológico de Antioquia \\ Facultad de Derecho y Ciencias Forenses \\ Coordinadora del semillero multidisciplinar de \\ ciencias forenses \\ Grupo de investigación BISMA \\ Docente investigadora. Bióloga. Magíster en \\ biotecnología y fisiología. Doctora en bioquímica, \\ farmacología y fisiología \\ Medellín, Colombia \\ aura.gil@tdea.edu.co
}

DOI: https://doi.org/10.53995/25390147.1013

El hacking ético analiza todas las vulnerabilidades de seguridad informática existentes en un sistema para poder mitigarlas; a su vez, desarrolla diferentes programas de defensa cibernética permanentes, basándose en diferentes leyes vigentes, las cuales varían según el continente. América latina adopta el convenio Budapest que supone una regulación internacional proporcionando una ayuda a los países para incluir medidas de ciberseguridad adecuadas, la cuales incluyen penas para ciberdelitos como accesos ilegales, interrupciones ilícitas de servicios, robos de datos, interrupción de sistemas; utilización indebida de aparatos, falsificación informática, fraude informático, pornografía infantil y delitos en materia de derechos de autor y propiedad intelectual. También existes otras legislaciones importantes, como la nueva ley Fintesh de México y Brasil; la legislación española, la ley China MLPS 2.0, la ley federal de Rusia, legislación de ciberseguridad de EEUU y, por último, la ley de ciberseguridad del continente europeo. Las anteriores se basan en el fundamento del hacking ético y la protección de datos. Por lo anterior, el objetivo de la presente investigación es identificar normativas de otros países en términos de ciberseguridad que podrían ser implementados en Colombia para mejorar el hacking ético y alcanzar un alto nivel de seguridad. Se sugiere adoptar en Colombia medidas incluidas en la legislación de ciberseguridad de EEUU, la ley Fintech de México - Brasil y la ley de ciberseguridad de China, ya que estas regulaciones tienen una misma orientación: proteger el sistema y la información. De igual manera, se incluiría una estrategia de prevención y control basada en enfoques técnicos y tecnológicos para mejorar tanto los factores políticos, económicos y sociales. 


\section{Reporte de Caso: Filicidio Materno con Enucleación Traumática de Globos Oculares}

\section{Diego Esteban Lozano Duque}

Tecnológico de Antioquia - Institución Universitaria

Facultad de Derecho y Ciencias Forenses

Semillero multidisciplinar de ciencias forenses

Grupo de investigación BISMA

Profesional en criminalística

Medellín, Colombia

dlozanod@tdea.edu.co

\section{Cristian Otálvaro Betancur}

Tecnológico de Antioquia - Institución Universitaria

Facultad de Derecho y Ciencias Forenses

Semillero multidisciplinar de ciencias forenses

Grupo de investigación BISMA

Profesional en criminalística

Medellín, Colombia

cotalvar@tdea.edu.co

\section{Aura María Gil Villa}

Tecnológico de Antioquia - Institución Universitaria Facultad de Derecho y Ciencias Forenses

Coordinadora del semillero multidisciplinar de ciencias forenses

Grupo de investigación BISMA

Docente investigadora. Bióloga. Magister biotecnología y fisiología. Doctora en bioquímica, farmacología y fisiología

Medellín, Colombia

aura.gil@tdea.edu.co

DOI: https://doi.org/10.53995/25390147.1013

La enucleación traumática ocular es un fenómeno que consiste en la extracción de los ojos; y que se puede generar en circunstancias violentas, ya sea premortem y postmortem, también en actos de homicidios y torturas, según los casos registrados por la literatura y etiología forense mundial. En este caso de estudio, ocurrido en la ciudad de Medellín Colombia, la progenitora es la causante de la extracción de los globos oculares y posterior asesinato de su hijo de seis años de edad; como hecho agravante, se evidencia según las experticias forenses, que esta enucleación se genera cuando el niño aún se encontraba con vida, haciendo aún más dramático este filicidio. Otro de los elementos relevantes para la investigación del caso fue el análisis psiquiátrico y toxicológico de la madre del menor, lo que permitió explicar las características de este fenómeno filicida, posiblemente debidas a trastornos psiquiátricos asociados al consumo de drogas. Este fenómeno particular y excepcional despierta todo interés forense en términos del por qué, cómo, con qué y cuándo puede rodear la muerte de este niño y otros niños o niñas en una sociedad que demuestra ausencia de empatía y de estrategias eficientes de protección de la infancia. 


\title{
Influencia de las Redes Sociales en la Ideación Suicida en Adolescentes del Corregimiento Sabaletas del Municipio de Montebello (Antioquia)
}

\author{
Leidy Caterine Molina Montoya \\ Tecnológico de Antioquia - Institución Universitaria \\ Psicología \\ Semillero Origen \\ Grupo de investigación suicidio \\ Medellín, Colombia \\ Leidy.molina@outlook.com
}

DOI: https://doi.org/10.53995/25390147.1013

Según la OMS, cada año se suicidan cerca de 703.00 personas en el mundo; esto corresponde a una muerte cada 40 segundos, en el 2019 fue la segunda causa de muerte entre los jóvenes de 15 a 29 años, después de los accidentes de tránsito.

Para Durkheim no son las personas las que se suicidan, es la sociedad la que se suicida a través de sus miembros; este autor fue quien dio el primer paso a pensar que este hecho no era puramente personal y que la sociedad también tiene una gran correlación. Frecuentemente, se cree que el suicidio ocurre solamente cuando las personas tienen problemas de depresión, baja autoestima, soledad, influencias que vienen desde el interior del individuo; sin embargo, no se puede dejar por fuera la influencia de la sociedad, gran causante de sufrimiento emocional con factores estresantes; interacción familiar; conyugal e interpersonal; estigmatización; problemas laborales y desigualdad social. Por medio de esta propuesta de investigación teórica y a través de la aplicación de instrumentos, se podrá argumentar la influencia de las redes sociales en la ideación suicida de los adolescentes del corregimiento sabaletas Municipio Montebello y cómo estas interfieren en sus vidas cotidianas y los afecta. 


\section{Herramienta Tipo Encuesta para la Resolución de un Caso Forense en Desaparición Forzada}

\author{
Ximena Monsalve Velásquez \\ Investigadora judicial \\ Estudiante profesional en criminalística \\ Tecnológico de Antioquia - Institución Universitaria \\ Facultad de Derecho y Ciencias Forenses \\ Medellín, Colombia \\ xmonsalv@correo.tdea.edu.co
}

\section{Johan Echeverri Ocampo}

Estudiante profesional en criminalística

Tecnológico de Antioquia - Institución Universitaria

Facultad de Derecho y Ciencias Forenses

Semillero multidisciplinar de ciencias forenses

Grupo de investigación BISMA

Medellín, Colombia

johanocampo2015@gmail.com

\author{
Natalia Andrea Restrepo Hernández \\ Magíster en antropología, línea antropología \\ biológica UdeA \\ Coordinadora semillero de estudios antropológicos- \\ SEA. Línea forense \\ Grupo Bioforense \\ Medellín, Colombia \\ nrestr11@tdea.edu.co
}

\author{
Marcela Zapata Nieto \\ Investigadora judicial, profesional en criminalista \\ Tecnológica de Antioquia - Institución Universitaria \\ Maestrante en criminología y ciencias forenses, \\ Universidad Autónoma de Tamaulipas \\ Integrante de los semilleros multidisciplinar de \\ ciencias forenses; estudios antropológicos-SEA y \\ juntanza \\ mzapat16@correo.tdea.edu.co
}

\section{Aura María Gil Villa}

Docente investigadora. Bióloga. Magíster en biotecnología y fisiología. Doctora en bioquímica, farmacología y fisiología

Tecnológico de Antioquia - Institución Universitaria Facultad de Derecho y Ciencias Forenses

Coordinadora del Semillero multidisciplinar de ciencias forenses

Grupo de investigación BISMA

Medellín, Colombia

aura.gil@tdea.edu.co

DOI: https://doi.org/10.53995/25390147.1013

La desaparición forzada, lejos de ser el resultado de problemáticas entre grupos armados y conflictos de Estado, claramente identificados, ha sido un desafío complejo, donde se han creado convergencias, actores con intereses políticos y económicos en distintos niveles; Colombia y México se encuentran ubicados en primer y segundo lugar, según las estadísticas, como los países en Latinoamérica con más casos de desaparición forzada, sin dejar a un lado la afectación directa de las familias víctimas de este delito; esta situación lleva a analizar y cuestionar cuáles son los procesos que se deben planear y ejecutar por los profesionales que hacen parte de las investigaciones de búsqueda de personas desaparecidas.

Es por esta razón, que se hace necesario y fundamental atender esta problemática desde la implementación de una ayuda académica y pedagógica para los profesionales involucrados en las investigaciones de desaparición forzada mediante una herramienta de procedimiento virtual dirigido a criminalistas y criminólogos latinoamericanos sobre búsqueda y recolección de restos óseos humanos. Esta herramienta será diseñada mediante la identificación de competencias que deberían impartirse en los procesos de formación de profesionales adscritos a universidades de educación superior en ambos países, así como también identificar las dificultades, falencias y obstáculos a los que se enfrentan las personas que se encuentran actualmente ejerciendo labores relacionadas con la búsqueda de víctimas de desaparición forzada. 


\section{Colombianos como Transportadores de Droga Ilegal}

\section{Daniela Montoya Quintero}

Tecnológico de Antioquia- Institución Universitaria

Facultad de Derecho y Ciencias Forenses

Semillero multidisciplinar de ciencias forenses

Grupo de investigación BISMA

Profesional en criminalística

Medellín, Colombia

daniela.montoya37@correa.tdea.edu.co

\section{Valentina Buitrago Quintero}

Tecnológico de Antioquia- Institución Universitaria Facultad de Derecho y Ciencias Forenses

Semillero multidisciplinar de ciencias forenses

Grupo de investigación BISMA

Profesional en criminalística

Medellín, Colombia

valentina.buitrago14@correo.tdea.edu.co

\section{Anggie Carolain Álvarez Cardona}

Tecnológico de Antioquia- Institución Universitaria

Facultad de Derecho y Ciencias Forenses

Semillero multidisciplinar de ciencias forenses

Grupo de investigación BISMA

Profesional en criminalística

Medellín, Colombia

anggie.alvarez@correo.tdea.edu.co

\author{
Aura María Gil Villa \\ Tecnológico de Antioquia-Institución Universitaria \\ Facultad de Derecho y Ciencias Forenses \\ Coordinadora del semillero multidisciplinar de \\ ciencias forenses \\ Grupo de investigación BISMA \\ Docente investigadora. Bióloga. Magíster en \\ biotecnología y fisiología. Doctora en bioquímica, \\ Farmacología y fisiología \\ Medellín, Colombia \\ aura.gil@tdea.edu.co
}

DOl: https://doi.org/10.53995/25390147.1013

Desde los años 60, el narcotráfico colombiano ha causado un gran impacto a nivel nacional e internacional, lo cual ha llevado a los traficantes a innovar en estrategias de transporte de droga, donde incluso personas del común, denominadas bodypackers, han llevado en su cuerpo esta sustancia ilegal. Fuentes de organismo de seguridad explican que las bandas criminales buscan la captación de estas personas en zonas marginales de Antioquia, Cundinamarca, Quindío, Norte de Santander, Risaralda y Valle del Cauca. Una vez son reclutadas, estas son trasladadas hasta ciudades donde se ubican los aeropuertos de operación o conexión internacional, como Bogotá, Rionegro, Palmira, Armenia, Cúcuta y Bucaramanga.

Por lo anterior, el objetivo de la presente propuesta de investigación es identificar las condiciones socioeconómicas que han influenciado el transporte corporal de droga ilegal en los departamentos de Antioquia, Cundinamarca, Quindío y Valle del Cauca en los últimos 10 años, para determinar las causales más significativas que han influenciado en este tipo de criminalidad. Para lograr este objetivo, se hizo una búsqueda bibliográfica en bases de datos, como pubmed, Science Direc y Scielo; y para ampliar la información, se diseñó un formulario con preguntas cerradas de opción múltiple dirigido a INPEC, policía antinarcóticos y comunidad o personas que han estado en la cárcel por este delito. 


\section{Disbiosis Causada por Consumo de Alcohol y Consecuencias en la Salud: una Revisión}

\author{
Valentina Ocampo Ramírez \\ Universidad Libre \\ Facultad ciencias de la salud \\ Grupo de investigación perteneciente al programa \\ DELFÍN \\ Pereira, Colombia \\ valentina-ocampor@unilibre.edu.co \\ Claudia Patricia Serna Giraldo \\ Tecnológico de Antioquia - Institución Universitaria \\ Facultad de Derecho y Ciencias Forenses \\ Semillero salud y célula \\ Grupo de investigación BISMA \\ Bacterióloga. Magister \\ Medellín, Colombia \\ cserna@tdea.edu.co
}

\author{
Aura María Gil Villa \\ Tecnológico de Antioquia - Institución Universitaria \\ Facultad de Derecho y Ciencias Forenses \\ Coordinadora del semillero multidisciplinar de \\ ciencias forenses \\ Grupo de investigación BISMA \\ Docente investigadora. Bióloga. Magíster en \\ biotecnología y fisiología. Doctora en bioquímica, \\ farmacología y fisiología \\ Medellín, Colombia \\ aura.gil@tdea.edu.co
}

DOI: https://doi.org/10.53995/25390147.1013

El consumo de alcohol de manera aguda o crónica en el humano ha demostrado ser el causante de disbiosis en la microbiota intestinal, alterando así la función de esta. La composición de la microbiota intestinal se identifica como única y específica en cada individuo, consistiendo en más de diez variedades de phylum, del cual el $90 \%$ de estas pertenece a los phylum Bacteroidetes y Firmicutes. Por su parte, las proteobacterias suelen ser bacilos anaerobios facultativos y gram negativos, los cuales contiene lipopolisacáridos que funcionan como biomarcadores de desequilibrio de la microbiota intestinal, ocasionando disfunción en el epitelio del intestino, padecimientos y una respuesta proinflamatoria. El consumo de alcohol causa sobrepoblación de bacterias en el intestino delgado, daño a la mucosa del colon; como consecuencia, un aumento en la permeabilidad intestinal; lo anterior genera una alteración de la barrera del intestino a causa del metabolismo del mismo etanol, ya que se induce estrés oxidativo mediante la acción de las enzimas alcohol deshidrogenasa y aldehído deshidrogenasa que convierten el etanol en acetato. 


\title{
La Aplicación de la Perspectiva de Género en la Intervención de Criminalista en Hechos de Feminicidio
}

\author{
Carolina Pacheco Mora \\ Universidad Autónoma de Tamaulipas \\ Unidad Académica Multidisciplinaria Reynosa \\ Aztlán \\ Reynosa, Tamaulipas, México \\ caropm56@gmail.com
}

DOl: https://doi.org/10.53995/25390147.1013

En los protocolos utilizados para realizar la investigación de hechos que se presumen como feminicidio, se expresa en el apartado de la investigación pericial que la perspectiva de género debe ser empleada para la búsqueda e interpretación de indicios, en ese sentido surge la siguiente incógnita: ¿Cómo se aplica la perspectiva de género en la investigación de la criminalística de campo en el lugar de investigación y en la emisión de dictámenes de hechos que se presumen como feminicidio? Para responder esta pregunta, se realizó un análisis comparativo entre los documentos Los servicios periciales con perspectiva de género, de la entonces Procuraduría General de la República, y el Modelo de protocolo latinoamericano de investigación de las muertes violentas de mujeres por razones de género, ya que el primero sugiere la aplicación de la perspectiva de género en la investigación del criminalista de campo en hechos que se presumen como feminicidio, el cual se toma como referencia del modelo de protocolo latinoamericano la interpretación de los indicios encontrados en el lugar para la posterior emisión del dictamen. Igualmente, se llevó a cabo un estudio sobre el uso de la perspectiva de género para la interpretación de indicios en las diversas especialidades forenses que se requieren para emitir el dictamen de mecánica de hechos y posición víctima-victimario.

De acuerdo con el texto Los servicios periciales con perspectiva de género, se sugiere que la interpretación de los indicios con perspectiva de género puede ser aplicada por cualquier área de la ciencia forense, incluida la criminalística. Sin embargo, el Modelo de protocolo latinoamericano de investigación de las muertes violentas de mujeres por razones de género solo menciona la interpretación de indicios que pueden estar relacionados con la víctima y el victimario, de acuerdo al lugar de los hechos o del hallazgo, por lo que no se enuncia la aplicación de la perspectiva de género como método de ayuda para el trabajo propiamente del criminalista. como es la interpretación de los diversos indicios para emitir un dictamen en mecánica de hechos y posición víctima-victimario.

El modelo de protocolo si bien enuncia la importancia de la perspectiva de género, en materia de criminalística no establece de manera específica cómo el criminalista de campo debe aplicarla en el lugar de investigación con relación al método de la criminalística de campo, pues solo se menciona de manera generalizada la aplicación de la debida diligencia. Por otro lado, si bien sí se enuncia la importancia de la emisión del dictamen en mecánica de hechos, no existe un apartado específico sobre la formulación de este utilizando la perspectiva de género de forma interpretativa de los diversos dictámenes que se analizan para la emisión del mismo. 


\title{
El Enigma de los Asesinatos de Líderes Sociales en el Pacífico Colombiano y su Relación con las Industrias Extractivas
}

\section{Yennesit Palacios Valencia}

Tecnológico de Antioquia - Institución Universitaria Facultad de Derecho y Ciencias Forenses

Semillero de investigación derechos humanos, género y multiculturalismo

Medellín, Colombia

yennesit.palacios@tdea.edu.co

\section{Juan Pablo Muñoz Giraldo}

Tecnológico de Antioquia - Institución Universitaria

Facultad de Derecho y Ciencias Forenses

Semillero derechos humanos, género y

multiculturalismo

Grupo de investigación jurídico social

Medellín, Colombia

juan.munoz80@correo.tdea.edu.co
Kevin Sánchez Pabón

Tecnológico de Antioquia - Institución Universitaria Facultad de Derecho y Ciencias Forenses

Semillero derechos humanos, género y multiculturalismo

Grupo de investigación jurídico social

Medellín, Colombia

kevin.sanchez23@correo.tdea.edu.co

\section{Valentina Villacob Galezo}

Tecnológico de Antioquia - Institución Universitaria

Facultad de Derecho y Ciencias Forenses

Semillero derechos humanos, género y

multiculturalismo

Grupo de investigación jurídico social

Medellín, Colombia

valentina.villacob@correo.tdea.edu.co

DOI: https://doi.org/10.53995/25390147.1013

\begin{abstract}
A los asesinatos de líderes sociales en Colombia, por un lado, como consecuencia del conflicto armado, se ha sumado un factor determinante, como lo es la proliferación de las industrias extractivas, las cuales han generado graves impactos socioambientales dentro de comunidades étnicas. Por otro lado, también se encuentran las disputas entre diferentes grupos armados ilegales por la obtención del control sobre territorios que, por su riqueza en recursos naturales, inter alias, antes de la Firma de los Acuerdos de Paz, eran controlados por las guerrillas de las Fuerzas Armadas Revolucionarias de Colombia (FARC). En este escenario, diferentes grupos delincuenciales han ejercido actividades como el narcotráfico, la extorsión y la minería ilegal; actividades que no solo financian políticas de guerra, sino que también les permite propiciar desplazamientos forzados, intimidaciones, asesinatos y violaciones de derechos humanos en diferentes zonas del país, destacándose el área del Pacífico colombiano. Puntualmente, los departamentos como el Chocó, Cauca, Nariño y Valle del Cauca, pues debido a su posición geográfica y por la abundancia en recursos hídricos, los grupos armados se ven favorecidos para delinquir y desarrollar procesos extractivos como la minería ilegal del oro. En consecuencia, se evidencia en esta investigación la preocupación por el aumento progresivo de asesinatos a líderes sociales después de la firma del Acuerdo de Paz con las FARC.
\end{abstract}




\section{Procesos de Justicia Transicional sin Transiciones: Estudio Relativo a Colombia y España}

\author{
Yennesit Palacios Valencia \\ Tecnológico de Antioquia - Institución Universitaria \\ Facultad de Derecho y Ciencias Forenses \\ Semillero de investigación derechos humanos, \\ género y multiculturalismo \\ Medellín, Colombia \\ yennesit.palacios@tdea.edu.co \\ Naybet Yepes Zapata \\ Tecnológico de Antioquia Institución Universitaria \\ Facultad de Derecho y Ciencias Forenses \\ Semillero de investigación derechos humanos, \\ género y multiculturalismo \\ Medellín, Colombia \\ naybet.yepes@correo.tdea.edu.co
}

\section{Geraldine Gil Álvarez}

Tecnológico de Antioquia - Institución Universitaria Facultad de Derecho y Ciencias Forenses

Semillero de investigación derechos humanos, género y multiculturalismo

Medellín, Colombia

geraldine.gil57@correo.tdea.edu.co

DOl: https://doi.org/10.53995/25390147.1013

Los conflictos armados, los fenómenos dictatoriales, las guerras civiles, y muchas otras formas de conflicto, a lo largo de la historia, han evidenciado, pese al amplio corpus iuris internacional existente, para la protección de los derechos humanos, su incumplimiento. Esto, tanto en el sistema interamericano de protección de los derechos humanos, como en su homólogo, en el ámbito europeo. Por ello, fue menester concretar el estudio en procesos de justicia transicional para el cumplimiento de dichos estándares, en lo relativo a la verdad, justicia, reparación, memoria histórica y medidas de no repetición. Como modelo de estos procesos se destaca el caso colombiano, donde después de un conflicto armado consolidado desde la década de los 60s, se instituyó un acuerdo negociado con la Guerrilla de las Fuerzas Armadas Revolucionarias de Colombia (FARC), en La Habana, Cuba. Por otro lado, muy distinto al caso colombiano, la guerra civil y el régimen franquista en España derivaron en una transición democrática que no atendió a los derechos de las víctimas después de su caída y se gestó una transición, pero sin justicia transicional. Si bien, ambos procesos son totalmente distintos, la investigación desarrolla una comparación entre los dos casos para entender los diferentes modelos de transición y las tensiones resultantes en relación a los derechos de las víctimas. 


\section{Reservorio la Diversidad: Colección de ADN de Moscas de Importancia Forense del Tecnológico de Antioquia}

\author{
Hernán Alejandro Pineda Henao \\ Tecnológico de Antioquia - Institución Universitaria \\ Facultad de Derecho y Ciencias Forenses \\ Semillero insecta \\ Grupo de investigación Bioforense \\ Medellín, Colombia \\ hernan.pineda16@correo.tdea.edu.co
}

\section{Orianna Tamara Vivares}

Tecnológico de Antioquia - Institución Universitaria Facultad de Derecho y Ciencias Forenses

Semillero insecta

Grupo de investigación Bioforense

Medellín, Colombia

orianna.tamara@correo.tdea.edu.co

\section{Andrés Felipe maya}

Tecnológico de Antioquia - Institución Universitaria

Facultad de Derecho y Ciencias Forenses

Semillero insecta

Grupo de investigación Bioforense

Medellín, Colombia

anfemadu@gmail.com

\section{Luz Miryam Gomez Piñerez}

Tecnológico de Antioquia - Institución Universitaria

Facultad de Derecho y Ciencias Forenses

Semillero insecta

Grupo de investigación Bioforense

Medellín, Colombia

lgomez@tdea.edu.co

DOI: https://doi.org/10.53995/25390147.1013

En la entomología forense, el ADN (Ácido desoxirribonucleico) sirve como herramienta complementaria para la identificación taxonómica, la cual facilita la estimación precisa del tiempo transcurrido desde la muerte. Para su uso se requiere que el ADN se extraiga de manera eficiente, en un estado adecuado para su empleo en procedimientos moleculares y que se pueda almacenar a largo plazo. Tradicionalmente, la conservación del ADN se ha realizado en refrigeradores a $-20^{\circ} \mathrm{C}$ y $-80^{\circ} \mathrm{C}$, metodología que requiere gran espacio físico, uso de energía y establecimiento de protocolos que eviten los riesgos de descongelamiento por fallos energéticos. Para evitar la degradación del ADN y optimizar espacio, las tarjetas FTA Classic Card (Flinders Technology Associates) proporcionan una alternativa ideal para el almacenamiento; contiene sustancias químicas que desnaturalizan las proteínas y protegen el ADN, son de fácil utilización, almacenamiento y proceso de intercambio. Además, el contenido de la tarjeta puede utilizarse directamente en técnicas de PCR (Reacción en cadena de la polimerasa).

El presente trabajo tiene por objeto emplear este método de almacenamiento de la información genética con el propósito de contribuir a la conservación de especies por medio de la consolidación de la colección de ADN de moscas de importancia forense del Tecnológico de Antioquia, lo que facilitará su estudio, desarrollo de metodologías para futuros proyectos que requieran análisis génico y un respaldo de la información genética de cada especie que puede ser utilizada como referencia para la identificación en el contexto de la entomología forense. 


\title{
La Incidencia del Discurso de Odio en la Comisión de Delitos de Altos Impacto desde el Sistema Interamericano de Protección de Derechos Humanos
}

\author{
María Eugenia Présiga Osorio \\ Tecnológico de Antioquia - Institución Universitaria \\ Estudiantes de maestría en ciencias forenses y \\ criminalística \\ Carlos Mario Vanegas Calle \\ Tecnológico de Antioquia - Institución Universitaria \\ Estudiantes de maestría en ciencias forenses y \\ criminalística
}

DOI: https://doi.org/10.53995/25390147.1013

El discurso de odio cimentado en prejuicios de diverso cuño ha sido la génesis de innumerables delitos que atentan contra la dignidad humana y los instrumentos internacionales que protegen los derechos humanos, el convulsionado siglo XX heredó los fanatismos y nacionalismos del siglo XIX, soportados en la supuesta superioridad biológica de algunos países, que se auto atribuían el liderazgo mundial basados en una geografía binaria que divide el mundo en desarrollosubdesarrollo, ricos-pobres, blancos y negros, bajo supuestos de una identidad cultural. Con el presente producto se pretende identificar los crímenes de alto impacto que se han cometido en algunos países de Latinoamérica, perpetrados por expresiones de odio que atentan contra las garantías de derechos en personas o grupos vulnerables que requieren una protección reforzada. 


\title{
Análisis Comparativo de los Modelos Criminalísticos en México
}

\author{
Jorge Luis Ramos Ramos \\ Universidad Autónoma de Tamaulipas \\ Unidad académica multidisciplinaria Reynosa- \\ Aztlán \\ Estado de México, México \\ a2203718018@alumnos.uat.edu.mx
}

DOI: https://doi.org/10.53995/25390147.1013

La criminalística en México se ha ido desarrollando tecnológicamente por su gran demanda, por lo que se han realizado diversos escritos para la operación de la misma con el propósito de poder usar los distintos instrumentos tecnológicos de manera adecuada y obtener de los mismos grandes resultados, pero dentro de la parte teórica no se ha tenido grandes cambios dentro de los modelos criminalísticos que se manejan en México, ya que en su mayoría estos modelos no han sufrido adaptaciones o cambios, de acuerdo a las necesidades actuales.

Los modelos criminalísticos a los que se hace referencia son aquellas concepciones que han tenido autores o instituciones sobre la criminalística y de las cuales se desarrolla conceptualmente la aplicación, principio, objetivos, fines y definiciones, entre otras cuestiones acerca de la misma. Además, el conjunto de estos modelos conforma a las escuelas o doctrinas de la criminalística, las cuales son: 1) Escuela jurídica. 2) Escuela de la investigación criminal. 3) Escuela criminológica. 4) Escuela contemporánea. Siendo esta última la más joven de todas.

La criminalística en México ha tenido grandes personajes que se han dedicado a la investigación y aportación teórica de la misma, de esa forma existen grandes personalidades dentro de dicha comunidad, como el Dr. Rafael Moreno González o el Capitán Juventino Montiel Sosa quienes se han dedicado, entre muchas otras cosas, a la aportación teórica de la criminalística, así como a la formulación de modelos teóricos, los cuales se han adoptado y enseñado dentro de la comunidad forense y estudiantil, pero de los cuales se han mantenido sin muchos cambios.

Solo hasta el año de 2017, el Dr. en derecho y criminalista Roberto Carlos Ramírez Aldaraca propone un nuevo paradigma de la criminalística en la que introduce un nuevo modelo criminalístico y en el que pretende resolver el problema teórico que existe en torno a la criminalística, de esa forma introduce un nuevo concepto de la criminalística, cuestiona algunos de los principios que existen de la criminalística y propone unos nuevos en la que combina los principios de la lógica y los principios de aquella, para dar paso a los lógicos-criminalísticos, que ayudan en el proceso de la obtención de una verdad objetiva de algún hecho que se investiga y de los cuales no necesariamente están vinculados con un delito.

De esa forma, se realizó un análisis comparativo de los principales modelos que existen de la criminalística en México con el propósito de conocer el valor teórico de cada una de estas, así como las similitudes y diferencias que hay en cada una de estas, para finalmente mencionar cuál aporta el mayor número de elementos científicos y objetivos. 


\title{
La Salud como Derecho Fundamental Autónomo - a través del Análisis Jurisprudencial de la Sentencia T-760 de 2008
}

\author{
José Mauricio Arredondo Del Río \\ Tecnológico de Antioquia - Institución Universitaria \\ Facultad de Derecho y Ciencias Forenses \\ Semillero de investigación seguridad social - El \\ derecho a la salud como derecho fundamental - \\ Sentencia T-760/2008 \\ Grupo de investigación jurídico social \\ Medellín, Colombia \\ jmarredondo@tdea.edu.co

\section{Juan Pablo Muñoz Giraldo} \\ Tecnológico de Antioquia - Institución Universitaria \\ Facultad de Derecho y Ciencias Forenses \\ Semillero de investigación seguridad social - El \\ derecho a la salud como derecho fundamental - \\ Sentencia T-760/2008 \\ Grupo de investigación jurídico social \\ Medellín, Colombia \\ juan.munoz80@correo.tdea.edu.co
}

DOI: https://doi.org/10.53995/25390147.1013

A través de la Sentencia T-760 de 2008, la Corte Constitucional reafirmó que la salud es un derecho fundamental autónomo, señalando que la calidad fundamental de un derecho no depende de la vía procesal mediante la cual se haga efectivo, sino de su estrecha relación con la dignidad humana. El pronunciamiento del alto tribunal constitucional demostró las fallas estructurales del sistema de salud desde la Ley 100 de 1993 al realizar el estudio de 22 acciones de tutela que constataban la frecuente vulneración del derecho a la salud por parte de las entidades encargadas de la prestación de salud; por otro lado, se examinó las obligaciones legales internacionales del Estado en relación al derecho objeto de estudio, especialmente la Observación General Nro. 14 del Comité de Derechos Económicos y Culturales de la ONU., la cual resalta la obligación de garantizar a toda persona el acceder a los servicios de salud de manera oportuna, eficaz y con calidad, permitiendo así una cobertura universal; por lo tanto, en caso de vulneración al derecho a la salud, se puede solicitar su protección por medio de la acción de tutela de manera autónoma, sin necesidad de alegar la violación en conexidad con la vida 0 a la integridad personal. 


\title{
Perfil Criminal de Homicidas Políticos Comparado al de Perpetradores de Ejecuciones Extrajudiciales en Colombia entre los Años 2002 y 2010
}

\author{
Mariana Rivera Palacio \\ Tecnológico de Antioquia - Institución Universitaria \\ Facultad de Derecho y Ciencias Forenses \\ Semillero multidisciplinar de ciencias forenses \\ Grupo de investigación BISMA \\ Profesional en criminalística \\ Medellín, Colombia \\ mariverapalacio@gmail.com \\ Aura María Gil Villa \\ Tecnológico de Antioquia - Institución Universitaria \\ Facultad de Derecho y Ciencias Forenses \\ Coordinadora del semillero multidisciplinar de \\ ciencias forenses \\ Grupo de investigación BISMA \\ Docente investigadora, Bióloga. Magister en \\ biotecnología. Doctora en Bioquímica, Farmacología \\ y fisiología \\ Medellín, Colombia \\ aura.gil@tdea.edu.co
}

DOl: https://doi.org/10.53995/25390147.1013

La perfilación criminal es una técnica de investigación judicial, que permite reconocer aquellos aspectos psicosociales presentes en el agresor por medio de un estudio psicológico, criminalístico y forense sobre sus crímenes, con el único fin de identificar a qué tipo de persona se hace referencia y cómo se encaminará la investigación. A lo largo del artículo, se pretenderá analizar los diferentes tipos de perfiles criminales existentes en la literatura científica, con el propósito de individualizar una de las tipologías criminales que más relevancia ha tenido para la psicología y la criminología, la cual es denominada como "homicidas políticos". Asimismo, se desea exhibir el perfil criminal de los perpetradores de las ejecuciones extrajudiciales o también conocidas como "falsos positivos" en Colombia durante el periodo presidencial de la seguridad democrática, el cual tuvo vigencia entre los años 2002 y 2010; entendiéndose este período como un suceso crítico para la reconstrucción de la memoria histórica del país por el alto índice de víctimas que dejó a su paso. Por lo anterior, el estudio de estos perfiles permitirá resaltar la similitud entre sus características criminales; características que se centrarán en la principal motivación e ideología presente entre ambos perfiles, comprendiendo que las motivaciones pueden ser religiosas, políticas e incluso sociales para logar un objetivo, sin importar los medios usados. Así, se pretende clasificar a los perpetradores de las ejecuciones extrajudiciales en una de las tipologías criminales existentes y entendiendo el fundamento principal para desarrollar estos crímenes de lesa humanidad. 


\section{Conocimiento y Uso de Cannabinoides Sintéticos en Estudiantes del Tecnológico de Antioquia - Institución Universitaria, Medellín, 2020}

\author{
Melisa Valencia Quintero \\ Profesional en criminalística \\ natalimelisa@hotmail.com \\ Evelyn Díaz \\ Profesional en criminalística \\ evelyn.ac327@gmail.com \\ Geraldine Ramírez Cardona \\ Profesional en criminalística \\ geralr234@gmail.com
}

\author{
Kelly Dallana Zapata García \\ Profesional en criminalística \\ investigadora.kelly.zapata@gmail.com \\ Laura Alejandra Rodríguez \\ Profesional en criminalística \\ lauralejandrarodriguez@gmail.com \\ Maira Alejandra Martínez Barrios \\ Profesional en criminalística \\ aheris@hotmail.es
}

DOI: https://doi.org/10.53995/25390147.1013

Establecer los factores asociados con el uso de cannabinoides sintéticos en la comunidad académica del Tecnológico de Antioquia. Este estudio de corte transversal en estudiantes de esta institución se aplicó con una encuesta de manera electrónica para indagar sobre el uso de canabinnoides sintéticos durante el segundo semestre del 2020. Se realizó la prueba de Chi cuadrado para establecer asociaciones con el grado conocimiento y uso canabinnoides de sintéticos.

Según la prueba, el 1,1\% refirió consumo de esta sustancia. Los factores asociados con el uso fueron se usuario de marihuana OR 27,2 IC 95\%1,7-469 valor $p<.001$ o cocaína OR 23,5 IC $95 \% 4,5-124$ valor $\mathrm{p}<.001$.

Esto demuestra que el consumo de los cannabinoides sintéticos es bajo en el Tecnológico Antioquia, pero existe una clara relación de este consumo con el uso de otras drogas de abuso, lo que implica que esta sustancia está ingresando al mercado regional, colocando en riesgo a los universitarios de la ciudad. 


\title{
Análisis de las Técnicas de Estudio en Huellas de Mordedura Humana y su Aplicación en el Campo Forense de la Ciudad de Reynosa, Tamaulipas
}

\author{
Diana Marcelina Villegas García \\ Universidad Autónoma de Tamaulipas \\ Maestría en criminología y ciencias forenses \\ Reynosa, Tamaulipas, México \\ a2201730258@alumnos.uat.edu.mx
}

\section{DOI: https://doi.org/10.53995/25390147.1013}

La estomatología forense es la disciplina que aplica conocimientos estomatológicos para el correcto examen, manejo, valoración y presentación de las pruebas bucodentales en interés de la justicia. Esta especialidad colabora con la criminalística en la investigación y comprobación de ciertos delitos; ocupa una parte importante dentro de las ciencias forenses y es cada vez más utilizado en los casos de violencia doméstica, violencia de género y abuso infantil para identificar al agresor.

Las huellas de mordedura están presentes en muchos delitos y, por lo general. no causan la muerte, pero en donde esta se presenta, constituye una prueba estomatolegal que puede establecer la participación directa de un sujeto.

La importancia $y / 0$ el valor probatorio que puede llegar a tener las huellas de mordeduras encontradas en la escena de un crimen son tan importantes como cualquier otro indicio que se pueda hallar.

Mientras la literatura científica especializada, y más actual, de países como España, Estados Unidos, Ecuador, Colombia, ofrece una permanente o periódica revisión y actualización de esta pericia y de peritos en estomatología forense, la literatura de México no sostiene un ritmo similar, con una escasa o nula actualización de contenidos adecuados en procedimientos, investigación o reporte de casos, conlleva a una limitada información de casos de huellas de mordedura humana en la ciudad de Reynosa.

Cuando los dientes son usados como arma de defensa o de ataque, se requiere el estudio y análisis de las huellas de mordedura humana. Otra razón de la investigación es ampliar los estudios existentes entre las técnicas para analizar huellas de mordedura, así mismo, la finalidad es proporcionar información precisa y justificada en determinar las ventajas y desventajas de cada una de las técnicas, a través de modelos experimentales.

La informática y la tecnología 3D abren una nueva etapa en este tipo de análisis identificativo, recientemente el departamento de medicina legal y forense en colaboración con el departamento de lenguajes informáticos de la Universidad de Granada han desarrollado un nuevo programa informático con fines forenses, llamado DentalPrint (C). Con este software, el proceso se vuelve completamente automático, eliminando la subjetividad del observador. Autores reconocen que son necesarios más estudios para establecer rangos científicos en el uso del DentalPrint(C, por lo que la propuesta en este trabajo de investigación es evaluar su efectividad, aplicarla en modelos experimentales y proponer su aplicación en el campo forense en esta ciudad. 


\title{
La Hermenéutica Constitucional como Instrumento Legitimador de la Decisión Judicial en los Fallos de Tutela en Colombia
}

\author{
Santiago Zuluaga Vanegas - Director \\ Ana María López Botero/ Lesly Katerine Paniagua \\ Hernández \\ Semillero de investigación: filosofía del derecho y \\ decisión judicial \\ Facultad de Derecho y Ciencias Forenses \\ Tecnológico de Antioquia - Institución Universitaria \\ Medellín, Colombia \\ santiago.zuluaga69@tdea.edu.co
}

DOI: https://doi.org/10.53995/25390147.1013

La hermenéutica constitucional puede ser vista como un instrumento legitimador de la decisión judicial en los fallos de tutela, debido que en el neo constitucionalismo, el juez y su poder interpretativo adquieren una mayor relevancia, buscando acercar el derecho a la realidad, equilibrando así los defectos sociales.

En este sentido, se puede afirmar que la decisión judicial no se puede abordar como un mero silogismo o cadenas de silogismos, sino por el contrario se debe observar que detrás del texto judicial se esconde un universo entero de fenómenos y particularidades. Ahora bien, esta propuesta tiene como objetivo principal analizar cómo el juez utiliza la hermenéutica constitucional como un instrumento legitimador de la decisión judicial en los fallos de tutela en Colombia, por medio de una metodología teórica analítica, la cual consiste en una descomposición de un todo, individualizando cada parte o elemento del fenómeno de estudio. 


\title{
Redes Neuronales: de las Hormigas a la Mitigación de los Embotellamientos en la Cuidad
}

\author{
Jean Pierre Zuluaga Hernández, \\ Andrés Felipe Maya, Andrés López Rubio \\ Tecnológico de Antioquia - Institución \\ Universitaria \\ Facultad de Derecho y Ciencias Forenses \\ Semillero de bioinformática \\ Grupo Bioforense \\ jean.zuluaga@correo.tdea.edu.co
}

DOI: https://doi.org/10.53995/25390147.1013

La movilidad dentro de la cuidad se ha vuelto compleja: vías con gran densidad vehicular, colapsos masivos de las mismas, aumento de la accidentalidad, causando una afectación general en la movilidad. Para estudiar la dinámica de la movilidad se ha propuesto el uso de redes neuronales. Estas se definen como sistemas que simulan un conjunto de neuronas para generar procesos de pensamiento y toma de decisiones, usados para el estudio de fenómenos naturales y artificiales que se componen de una gran cantidad de variables y constituyen grandes bancos de información. En el reino animal existen seres vivos con niveles de sociabilidad, como las hormigas, cuyos patrones de forrajeo y alimentación permiten el estudio de las dinámicas del movimiento de grandes densidades de individuos. En esta propuesta se explorará el uso de redes neuronales para investigar los patrones de tráfico que afectan la movilidad, con base en los patrones de movilidad de las hormigas. Se espera que llegando a conocer estos patrones, se pueda llevar a cabo un análisis profundo de la circulación vehicular, mejorando la movilidad de la ciudad mediante una mejor toma de decisiones. 


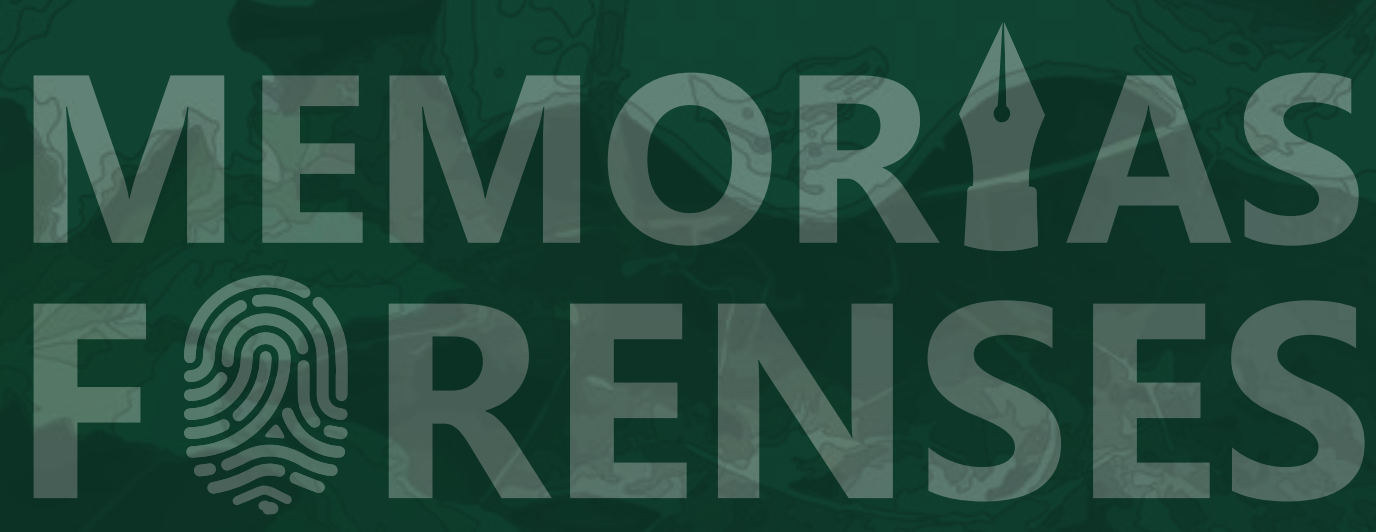

